\title{
A new device for the freeze-clamping of tissue samples
}

Quistorff, Bjørn; Pedersen, E.

Published in:

Analytical Biochemistry

Publication date:

1976

Document version

Publisher's PDF, also known as Version of record

Citation for published version (APA)

Quistorff, B., \& Pedersen, E. (1976). A new device for the freeze-clamping of tissue samples. Analytical Biochemistry, 73, 236-239. 


\section{A New Device for the Freeze-Clamping of Tissue Samples}

Measurement of metabolite concentrations in tissue samples involves the following procedures: Removal of the sample from the animal, temporary arrest of metabolism, extraction (including weighing, homogenization, final fixation, and neutralization) and assay. Rapid temporary fixation following the sampling of tissue is essential to prevent autolytic changes in metabolite concentrations $(1,2)$. The freeze-clamping technique described by Wollenberger et al. (3) meets this requirement as long as the final thickness of the freeze-clamped sample is sufficiently small. For brain tissue the limit seems to be about $2 \mathrm{~mm}$ (4).

In our laboratory we have made extensive use of the freeze-clamping tongs of Wollenberger et al., especially for small tissue samples freezeclamped in situ. However, when in situ clamping can not be used or when more than 2-3 g of tissue must be sampled, the freeze-clamping press described below has proven very useful.

\section{METHODS AND MATERIALS}

Figure 1A shows the manually operated version of the freeze-clamping press in closed position fitted in a wooden block. The two clamping surfaces on the cylindrical aluminium blocks are made semispherical in order to enlarge the cooling surface (Fig. 2A). The cross bars on the shafts are adjustable and prevent the blocks from hitting the bottom of the Dewar flask when cooled in liquid $\mathrm{N}_{2}$.

Figures $1 \mathrm{~B}$ and $\mathrm{IC}$ show the automatic version of the press. Compressed air supplies power to a two-way cylinder via two valves connected in series. The upper valve is a two-way valve ${ }^{1}$. The press is operated at pressures from 3-10 atm, depending partly on the amount of tissue and partly on the final thickness desired for the freeze-clamped sample. The two cylindrical aluminium blocks between which freeze-clamping takes place are demountable and are cooled separately in liquid nitrogen. The lower block is placed on a PVC disk, which secures the correct postion of the block and insulates it against the metal base of the instrument (Fig. 2C). The upper block is connected to the shaft of the piston from the compressed air cylinder (Fig. 2C). In this position the centering is automatically secured by three bars (a,b,c on Fig. 2B), one of which is springloaded and must be activated when the block is removed.

1 The cylinder and the valves were purchased from Maxam Power, Chamborne. England. 


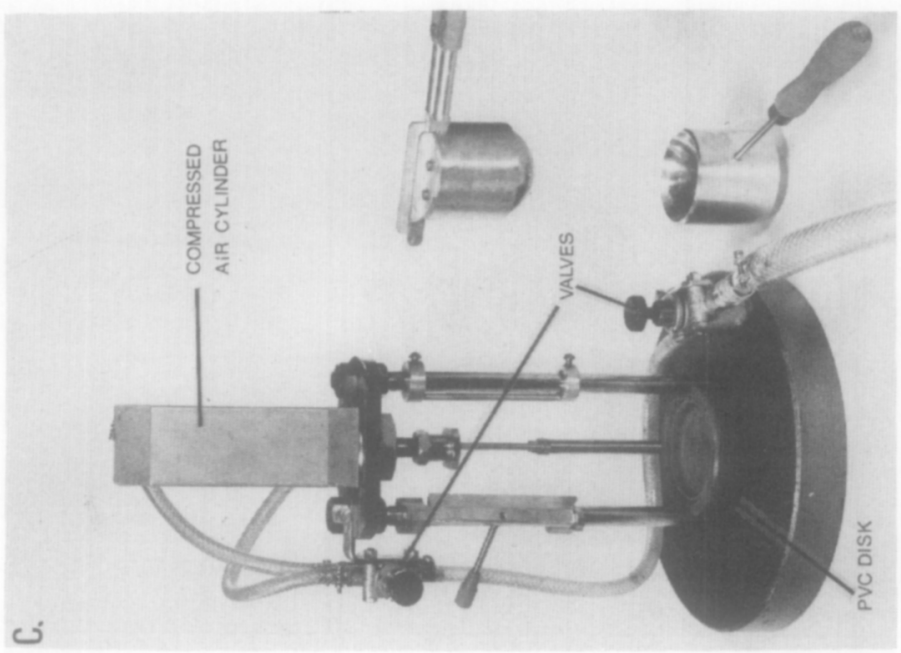

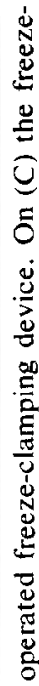
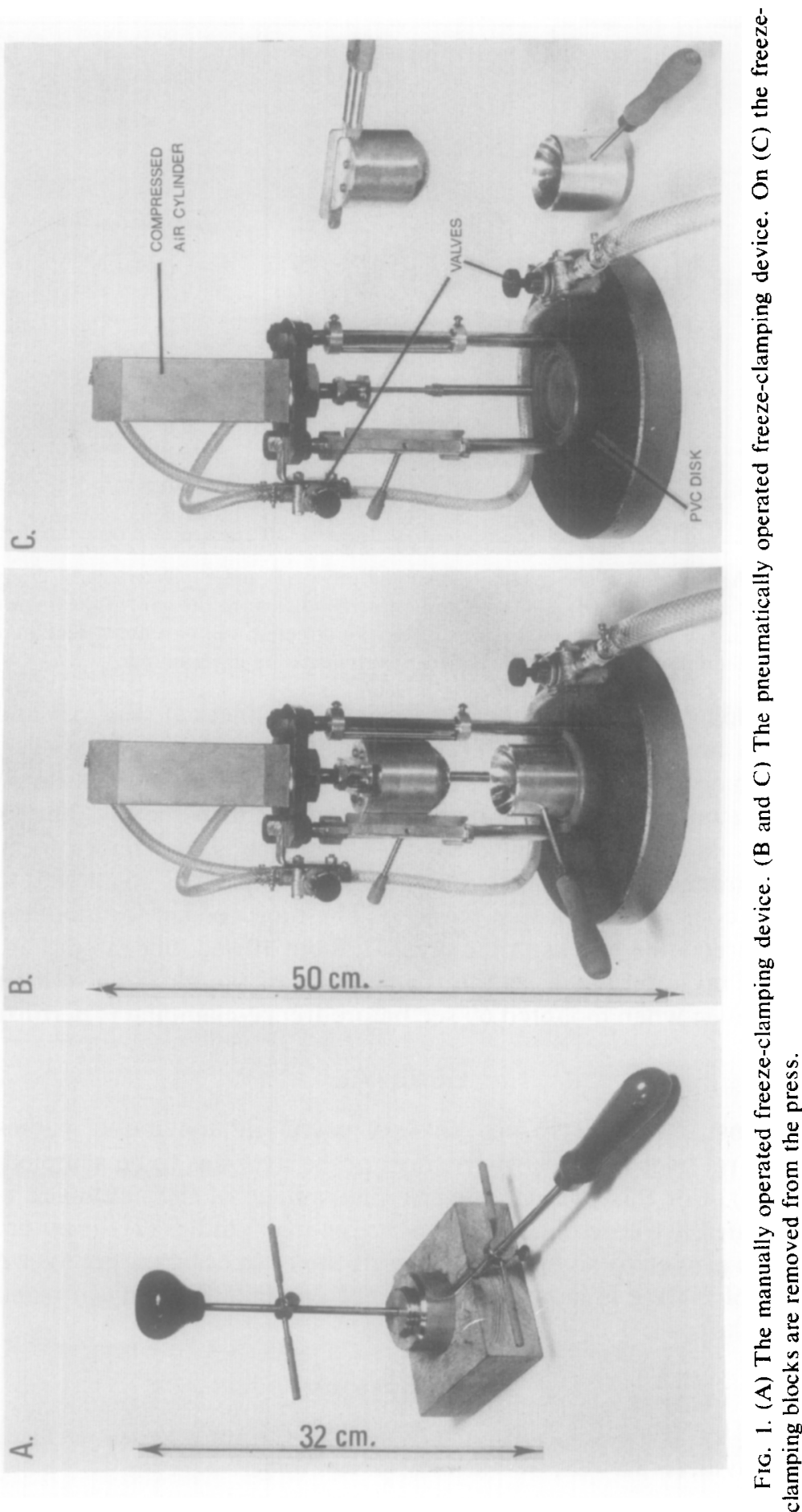


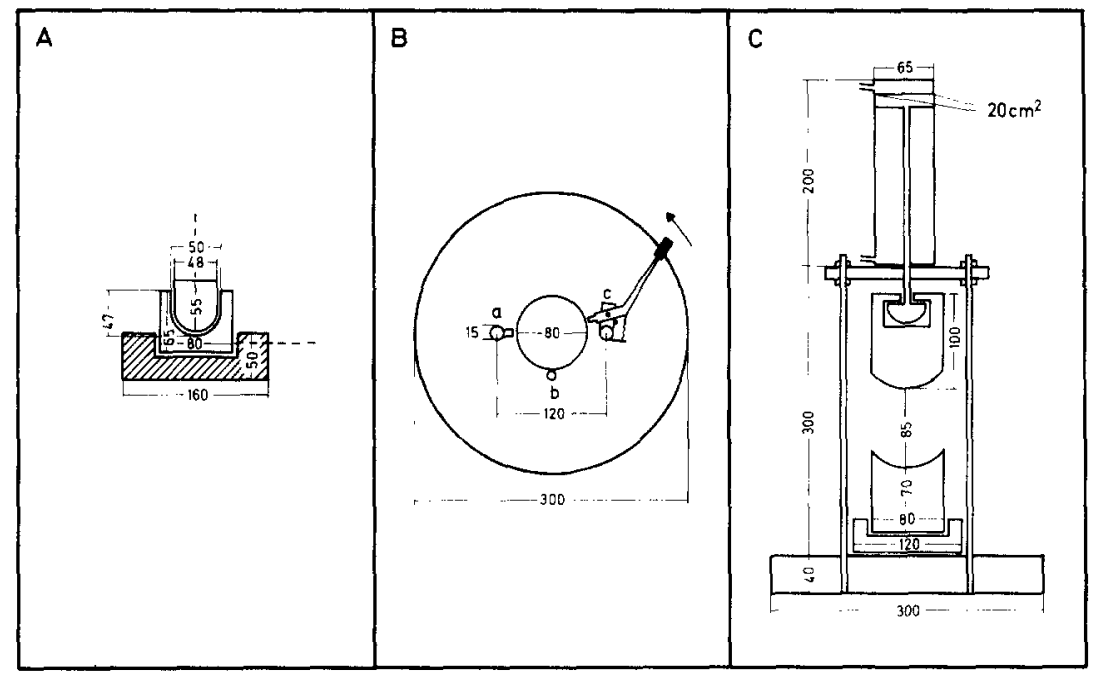

Fig. 2. (A) Diagram of the manually operated press. (B and C) Diagrams of the pneumatically operated press. (B) is a cross section perpendicular to the axis of the instrument showing how the movement of the upper block is directed. (C) is a cross section along the axis of the press. The dimensions of the instruments are given in $\mathrm{mm}$.

The clamping surfaces on the blocks are semispherical (Fig. 1B and C) giving an area of $100 \mathrm{~cm}^{2}$. This implies that for example, $8-10 \mathrm{~g}$ of tissue can be compressed to a $1-\mathrm{mm}$ thick shell-for muscle tissue giving a freezing time (i.e., cooling from 38 to $0^{\circ} \mathrm{C}$ ) of $0.16 \mathrm{sec}$ (3). The lower block has its own handle, whereas the upper one is transferred from the liquid nitrogen to the press by means of a pair of insulated tongs specially constructed for that purpose. The time needed for mounting of the two precooled blocks in the press is about $10 \mathrm{sec}$, but rapidity in this step is of no importance, as the temperature of the blocks is still below $-160^{\circ} \mathrm{C}$ even when mounted $60 \mathrm{sec}$ before freeze-clamping is performed.

\section{GENERAL}

Both instruments have proven very useful for metabolic studies on perfused rat liver in cases where most of the liver has to be sampled at a time $(5,6)$. For this purpose the main advantage of the automatic press is reproducible freeze-clamping. On the pig-liver studies (7) the automatic press has proven to be indispensable, as the rather fibrous pig liver in an amount of $5-10 \mathrm{~g}$ is impossible to freeze-clamp sufficiently in manually operated tongs.

\section{REFERENCES}

1. Lowry, O. H., and Possonneau, J. V. (1972) A Flexible System of Enzymatic Analysis, pp. 121-122. Academic Press, New York. 
2. Faupel, R. P., Seitz, H. J., Tarnowski, W., Thiemann, V., and Weiss, C. H. (1972) Arch. Biochem. Biophys. 148, 509-522.

3. Wollenberger, A., Ristau, O., and Schoffa, G, (1960) Pflügers Arch. 270, 399-412.

4. Quistorff, B., Eleff, S., Oshino, R., and Chance, B. (1975) in Proceedings of the 10th FEBS Meeting. (J. M. Tager et al., eds.), in press.

5. Kondrup, J. In preparation.

6. Quistorff, B. In preparation.

7. Lundquist, F., Sestoft, L., Fleron, P., and Damgaard, S. E. (1974) in Regulation of Hepatic Metabolism, pp. 302-313. (Lundquist, F.. and Tygstrup. N., eds.), Munksgaard, Copenhagen.

BJøRN QUISTORFF Egon Pedersen

Department of Biochemistry $A$

University of Copenhagen

Panum Institute

Blegdamsvej 3c

DK-2200 Copenhagen N, Denmark

Received December 15, 1975; accepted February 6, 1976 